\title{
Heptapeptide HP3 acts as a potent inhibitor of experimental imiquimod-induced murine psoriasis and impedes the trans-endothelial migration of mononuclear cells
}

\author{
ERNESTO A. VÁZQUEZ-SÁNCHEZ ${ }^{1,2}$, JOSÉ S. MENDOZA-FIGUEROA ${ }^{3}$, GUADALUPE GUTIÉRREZ-GONZALEZ ${ }^{1}$, \\ LUIS A. ZAPI-COLÍN ${ }^{1}$, AZAEL TORALES-CARDEÑA ${ }^{2}$, PAOLA E. BRISEÑO-LUGO ${ }^{4}$, \\ IVÁN DÍAZ-TOALÁ ${ }^{5}$, JUAN C. CANCINO-DIAZ ${ }^{6}$, SONIA M. PÉREZ-TAPIA ${ }^{7}$, MARIO E. CANCINO-DIAZ ${ }^{1}$, \\ FERNANDO GÓMEZ-CHÁVEZ ${ }^{2,8}$ and SANDRA RODRÍGUEZ-MARTÍNEZ ${ }^{1}$
}

\footnotetext{
${ }^{1}$ Laboratory of Innate Immunology, Department of Immunology, Escuela Nacional de Ciencias Biológicas (ENCB)-Instituto Politécnico Nacional (IPN), Mexico City $11340 ;{ }^{2}$ Department of Disciplinary Basic Formation, Escuela Nacional de Medicina y Homeopatía (ENMyH)-IPN, Mexico City 07320, Mexico; ${ }^{3}$ Department of Physics-Chemistry and Biology, Linköping

University, 58183 Linköping, Sweden; ${ }^{4}$ Department of Biological Sciences, Health Science Section, Facultad de

Estudios Superiores Cuautitlán, Universidad Nacional Autónoma de México (UNAM), Mexico City 54740;

${ }^{5}$ Department of Computational Systems Engineering, Escuela Superior de Cómputo-IPN, México City 07738;

${ }^{6}$ Laboratory of Immunomicrobiology, Department of Microbiology; ${ }^{7}$ National Laboratory for
}

Specialized Services for Research, Development and Innovation for Pharmacochemistry and Biotechnology products,

ENCB-IPN, Mexico City 11340; ${ }^{8}$ Laboratory of Experimental Immunology, Instituto Nacional de Pediatría,

Secretaría de Salud y Cátedras CONACyT, Instituto Nacional de Pediatría, Mexico City 04530, Mexico

Received September 20, 2019; Accepted April 02, 2020

DOI: $10.3892 / \mathrm{mmr} .2020 .11128$

\begin{abstract}
During the progression of psoriatic lesions, abundant cellular infiltration of myeloid cells, such as macrophages and activated dendritic cells, occurs in the skin and the infiltrating cells interact with naive lymphoid cells to generate a T helper (Th)1 and Th17 environment. Therapies to treat psoriasis include phototherapy, non-steroidal and steroidal drugs, as well as antibodies to block tumor necrosis factor- $\alpha$, interleukin (IL)-17-A and IL-12/IL-23, which all focus on decreasing the proinflammatory hallmark of psoriasis. The present study obtained the heptapeptide HP3 derived from phage display technology that blocks mononuclear cell adhesion to endothelial cells and inhibits trans-endothelial migration in vitro. The activity of the heptapeptide in a murine model of psoriasis was also assessed, which indicated that early administration inhibited the development of psoriatic lesions. Therefore, the results suggested that HP3 may serve as a potential therapeutic target for psoriasis.
\end{abstract}

Correspondence to: Dr Sandra Rodríguez-Martínez, Laboratory of Innate Immunology, Department of Immunology, Escuela Nacional de Ciencias Biológicas (ENCB)-Instituto Politécnico Nacional (IPN), Road Plan de Ayala y Prolongación de Carpio, Miguel Hidalgo, Col. Santo Tomás, Mexico City 11340, Mexico

E-mail: sandrarodm@yahoo.com.mx

Key words: psoriasis, peptide, phage display, inflammation, treatment

\section{Introduction}

Inflammation is a highly regulated natural biological phenomenon in which plasma molecules and leukocytes move to extravascular space as a secondary mechanism of endothelial activation in response to antigen recognition or damage-involved products (1). Psoriasis is a genetic disease triggered by several factors with the promotion of a proinflammatory environment, as well as dysfunctions in the regulation of inflammation in the skin with a crucial role in the maintenance of this pathology (2). Typical skin lesions in psoriasis contain abundant neutrophils, macrophages, activated plasmacytoid dendritic cells and dermal dendritic cells which interact with naive lymphoid cells to generate T helper (Th)1 and Th17 lymphocytes, as well as T regulatory (Treg) cells (3-5). A proposed etiology of psoriasis is the impaired function of Treg cells, possibly caused by the low expression of integrin $\beta$ chain- 2 [cluster of differentiation (CD)18] that favors the switch of Treg to Th17 environment, with the consequent increase in interleukin (IL)-17 that induces hyperproliferation of keratinocytes and angiogenesis (6). In this environment, infiltrated and local cells of the skin, produce several inflammatory mediators including tumor necrosis factor (TNF) $\alpha$, interferon $\alpha / \beta$, IL-1b, IL-6, IL-8, IL-17, IL-18, IL-23, IL-36, C-C motif chemokine ligand (CCL)2 (monocyte chemoattractant protein-1) and CCL5 $(5,7,8)$.

The treatments currently used for psoriasis focus primarily on the control of keratinocyte hyperproliferation and on the blockade of inflammatory mediators (9). Among these therapies are topic and systemic drugs, as well as phototherapy. Topic treatment with corticoids (including hydrocortisone, 
fluocinolones, betamethasone, mometasone and triamcinolone) and D vitamin analogs (calcitriol, calcipotriol and tacalcitol) are the most indicated drugs for patients with mild psoriasis, but topic retinoid tazarotene, salicylic acid, coal tar, anthralin and topic methotrexate are also used in these patients (10). Methotrexate, cyclosporine and acitretin have potent immunosuppressive effects and are indicated only for patients with severe psoriasis (11). More recently, the use of biological pharmaceuticals has increased for the treatment of psoriasis; adalimumab, infliximab, certolizumab and golimumab are antibodies that block the effect of TNF $\alpha$, while etanercept is an antibody that contains a portion of the TNF $\alpha$ receptor (12). Ustekinumab and briakinumab are also antibodies used in the treatment of psoriasis with specificity to protein-40, a common component of IL-12 and IL-23, which are involved in the differentiation of Th1 and Th17 cells, respectively $(13,14)$. IL-17 and IL-36 are cytokines strongly associated with the etiology of psoriasis and recently, anti-IL17 and anti-IL36 antibodies have been developed for the treatment of psoriasis and other inflammatory diseases, for example, secukinumab and ixekizumab block IL-17, whereas brodalumab binds to the IL-17 receptor $(15,16)$. ANB019 is an anti-IL36 receptor antibody that is still under clinical trial evaluation for the treatment of pustular psoriasis (17).

Adhesion molecules are also being used as a target to treat psoriasis (18-20). Lymphocyte function-associated antigen 1 (LFA-1), is expressed in all T-cells, B-cells, macrophages and neutrophils, and has been reported to be involved in the recruitment of such cells to the site of inflammation. LFA-1 binds to intercellular adhesion molecule 1 (ICAM-1) on antigen-presenting cells and functions as an adhesion molecule. Efalizumab is a humanized antibody anti-CD11 that blocks the interaction between LFA-1 and ICAM-1 expressed on endothelial cells. Alefacept is a chimeric molecule of human immunoglobulin G fused to LFA-3 (CD58) domain that recognizes LFA-2 (CD2) expressed in the surface of $\mathrm{T}$ lymphocytes, nevertheless, it was taken off the market due to its secondary effects (21).

The present study describes a heptapeptide obtained from cloning a library of phage peptides that in vitro blocked the adhesion of peripheral blood mononuclear cells (PBMCs) to endothelial cells and in vivo inhibited the development of murine psoriasis-like lesions. This peptide might be used in the future as a therapeutic peptide for the treatment of psoriasis.

\section{Materials and methods}

PBMCs. Peripheral blood $(6 \mathrm{ml})$ was obtained from a patient with acute laryngitis in tubes containing EDTA. The patient signed a written consent to participate in this study (the sample was taken on April 17th 2019). Peripheral blood mononuclear cells (PBMCs) were purified using Lymphoprep (Sigma-Aldrich; Merck KGaA) and centrifuged at $50 \mathrm{x} \mathrm{g}$ for $30 \mathrm{~min}$ at room temperature. Cells were maintained in DMEM medium (1 ml; cat. no. 11965-118, Gibco; Thermo Fisher Scientific, Inc.) without serum. Cell viability was analyzed using trypan blue and a cell suspension $\left(7.5 \times 10^{5}\right.$ viable cells $\left./ \mathrm{ml}\right)$ was prepared. The experiment was performed according to the appropriate guidelines for human use approved by the Institutional Committee of Bioethics of the Escuela Nacional de Ciencias Biológicas-IPN.
Selection of phages that recognized adhesion molecules expressed on PBMCs. PBMCs (1 ml) were washed with DMEM, diluted in $990 \mu \mathrm{l}$ TBS (50 mM Tris-HCl; pH 7.5; $150 \mathrm{mM} \mathrm{NaCl}$ ) and $10 \mu \mathrm{l}$ Phage Display peptide library Ph.D.-7 (New England Biolabs, Inc.) was added. PBMCs were incubated for $1 \mathrm{~h}$ at $37^{\circ} \mathrm{C}$ under $5 \% \mathrm{CO}_{2}$, with gentle agitation every $10 \mathrm{~min}$. The PBMCs-PH.D.-7 mix was washed six times with TBST [TBS $+0.1 \%(\mathrm{v} / \mathrm{v})$ Tween-20] and centrifuged at $50 \mathrm{x} g$ for $5 \mathrm{~min}$ at room temperature. The phages that bound to the PBMCs were eluted with $1 \mathrm{ml} 0.2 \mathrm{M}$ glycine- $\mathrm{HCl}(\mathrm{pH} 2.2)$ and neutralized with $150 \mu 11 \mathrm{M}$ Tris- $\mathrm{HCl}(\mathrm{pH} 9.1)$. Eluted phages were amplified by infecting Escherichia coli ER2738 (New England Biolabs, Inc.). Briefly, the eluate was added to $20 \mathrm{ml}$ mid-log phase E. coli ER2738 culture and incubated with vigorous shaking for $4.5 \mathrm{~h}$ at $37^{\circ} \mathrm{C}$. Subsequently, the solution was centrifuged for $10 \mathrm{~min}$ at $12,000 \mathrm{xg}$ at $4^{\circ} \mathrm{C}$. The supernatant was collected and the phages were precipitated by incubation with $20 \% \mathrm{PEG} / 2.5 \mathrm{M} \mathrm{NaCl}$ overnight at $4^{\circ} \mathrm{C}$. The phages were then retrieved by centrifugation at $12,000 \mathrm{x} \mathrm{g}$ for $15 \mathrm{~min}$ at $4^{\circ} \mathrm{C}$. Finally the phages were dissolved in $200 \mu \mathrm{l}$ TBS. The phages were quantitated by plaque forming units (PFU) in LB agar. The final concentration of phages was reported as plaque forming units per milliliter (PFU/ml). This selection and amplification of phages (biopanning) were repeated for two more rounds. After three rounds of selection, the eluted phages, able to interact with ligands over the surface of activated PBMCs, were dissolved in $200 \mu \mathrm{l}$ TBST containing $0.02 \% \mathrm{NaN}_{3}$ and stored for further assays. The total eluate was termed 'Total phages that interact with PBMCs' (TPhPBMCs). A non-related phage (PhNR) was obtained as a negative control.

Isolation of single phage clones. To obtain isolated clones from TPhPBMCs, TPhPBMCs dilutions $\left(10^{-5}-10^{-9}\right)$ were prepared in TBS. Subsequently, $10 \mu 1$ of each dilution was added separately to $200 \mu \mathrm{l} E$. coli ER2738 culture (mid-log growing phase), mixed with $3 \mathrm{ml}$ melt Top Agar (at $45^{\circ} \mathrm{C}$ ) and immediately spread over LB medium plates (Sigma-Aldrich; Merck KGaA). The plates were incubated at $37^{\circ} \mathrm{C}$ overnight. Subsequently, 10 plaques (single colonies) were randomly selected. E. coli ER2738 was then infected with each single clone independently to increase the chances that every colony forming unit contained only one peptide sequence. The procedure was repeated twice. The isolated clones were named $\mathrm{Ph}(1-10) \mathrm{PBMCs}$.

DNA extraction of phages, sequencing and analysis of the peptide sequence. According to the protocol provided by New England BioLabs, the extraction of phage DNA was performed using the $E$. coli culture supernatant, which was treated with $20 \% \mathrm{PEG} / 2.5 \mathrm{M} \mathrm{NaCl}$, and centrifuged at 4,400 $\mathrm{x}$ g for $10 \mathrm{~min}$ at $4^{\circ} \mathrm{C}$. The pellet was dissolved in $100 \mu \mathrm{l}$ iodide buffer and $250 \mu \mathrm{l}$ ethanol and incubated for 10-20 min at room temperature to precipitate preferentially single-stranded phage DNA, leaving most phage protein in solution. Finally, the pellet was retrieved after centrifugation at $1,700 \times \mathrm{g}$ for $15 \mathrm{~min}$ at $4^{\circ} \mathrm{C}$, and the phage DNA was dissolved in $30 \mu 1 \mathrm{TE}(10 \mathrm{mM}$ Tris + 1 mM EDTA; pH 8.0) buffer.

PCR was performed to verify the presence of the cassette containing the sequence that coded for the inserted peptide 
in the phage. The sequences of the oligonucleotides used were as follows: Forward, 5'-GCCGTTGCTACCCTC GTTC-3' and reverse, 5'-TTTCGGCCGAACCTCCACC-3'. The enzime used was AmpliTaq Gold ${ }^{\circledR}$ Fast PCR Master Mix (Applied Biosystems). The following thermocycling conditions were used for PCR: Initial denaturation for $10 \mathrm{~min}$ at $95^{\circ} \mathrm{C} ; 40$ cycles of denaturation at $96^{\circ} \mathrm{C}$ for $5 \mathrm{sec}$, primer alignment for $5 \mathrm{sec}$ at $60^{\circ} \mathrm{C}$ and extension for $5 \mathrm{sec}$ at $68^{\circ} \mathrm{C}$; followed by final extension at $72^{\circ} \mathrm{C}$ for $1 \mathrm{~min}$. Subsequently, sequencing was performed using the Sanger method and the primer-96pIII (5'-CCCTCATAGTTAGCGTAACG-3'). The sequences obtained for the inserted sequences were analyzed using NCBI BLAST software (version 2.2.25; National Center for Biotechnology Information).

Synthesis of heptapeptides. The heptapeptide HP3 and the non-related heptapeptide (HPNR, shuffled sequence of HP3) were manufactured by TAG Copenhagen A/S based on the sequence obtained from $\mathrm{Ph} 3 \mathrm{PBMC}$ DNA sequencing analysis.

Culture and stimulation of human microvascular endothelial cells (HMVECs). HMVECs (CRL-3243 ${ }^{\mathrm{TM}}$, dermal microvascular endothelium HMEC-1; American Type Culture Collection, https://www.atcc.org/products/all/CRL-3243. aspx) were cultured in endothelial growth medium (EGM, Lonza Group Ltd.) supplemented with MV BulletKit [Lonza Group Ltd.: Recombinant human(rh) epidermal growth factor, GA-100, hydrocortisone, Bovine Brain Extract (BBE) and 5\% FBS], incubated at $37^{\circ} \mathrm{C}$ in $5 \% \mathrm{CO}_{2}$ until $100 \%$ confluence was obtained. Then, $24 \mathrm{~h}$ before stimuli, HMVECs were incubated with supplemented EGM medium without FBS. HMVECs were stimulated $4 \mathrm{~h}$ with $50 \mathrm{ng} / \mathrm{ml} \mathrm{rhTNF} \alpha$ to induce adhesion molecule overexpression (data not shown) for further experiments.

Adherence inhibition assays. PBMCs were obtained from one healthy donor (age, 20 years; male) who provided written informed consent on May 1st 2019. A total of $2 \times 10^{6}$ PBMC were stained with $1 \mathrm{M}$ calcein (Thermo Fisher Scientific, Inc.) for $1 \mathrm{~h}$ at $37^{\circ} \mathrm{C}$ in $5 \% \mathrm{CO}_{2}$. Subsequently, PBMCs were washed three times with RPMI medium and centrifuged at $50 \mathrm{x} \mathrm{g}$ for $15 \mathrm{~min}$ at room temperature. PBMCs were maintained in RPMI medium. Calcein-stained PBMCs $\left(7.5 \times 10^{5}\right.$ cells $\left./ \mathrm{ml}\right)$ were incubated with different concentrations of phages or heptapeptides in RPMI medium without FBS for $1 \mathrm{~h}$ at $37^{\circ} \mathrm{C}$. The concentration of TPhPBMCs and PhNR used were $10^{3}-10^{9} \mathrm{PFU} / \mathrm{ml}$ and $10^{7} \mathrm{PUF} / \mathrm{ml}$ of $\mathrm{Ph}(1-10) \mathrm{PBMCs}$. Heptapeptides were used at $0.02-2.0 \mathrm{pg} / \mathrm{ml}$. After $2 \mathrm{~h}$ of incubation with phages or heptapeptides, PBMCs were washed twice with FBS-free DMEM and centrigued at $50 \mathrm{xg}$ for $5 \mathrm{~min}$.

Separately, HMVECs were grown in 12-well plaques and stimulated with rhTNF $\alpha$ as described above. Following stimulation, the medium with rhTNF $\alpha$ was removed and HMVECs were incubated for $1 \mathrm{~h}$ with $7.5 \times 10^{5}$ calcein-stained PBMCs pre-treated with phages or heptapeptides, as aformentioned. Non-adherent PBMCs were washed six times with DMEM without FBS. The adhered cells were observed by fluorescent microscopy or detached with Trypsin-EDTA (Gibco; Thermo Fisher Scientific, Inc.) to be acquired and analyzed by flow cytometry.
Analysis of cell adhesion by UV microscopy and flow cytometry. The counting of PBMCs-calcein positive cells adhered to HMVECs was performed in 5 different fields using fluorescent microscopy on every assayed condition. The average adherence of PBMCs-calcein positive cells to HMVECs stimulated with rhTNF $\alpha$ in the absence of phage or peptide was considered as $100 \%$ adherence (maximum adherence). Two-way ANOVA followed by Bonferroni's post hoc test was used to compare the different conditions.

For the flow cytometry analysis, the co-cultures were treated with trypsin and, after the second wash, the cells were maintained in FACS flow fluid. The acquisition of data was adjusted to $2.5 \times 10^{4}$ events of HMVECs (calcein-negative) and the percentage of calcein-positive PBMCs detected in each condition was determined. The total number of positive events was detected and analyzed in a FACSCalibur cytometer (BD Biosciences).

Trans-endothelial migration assay. HMVECs were cultured in the top chamber of Transwell plates $(5 \mu \mathrm{m}$ pore size, Costar, Corning Inc.) with EBM ${ }^{\mathrm{Tм}}$ supplemented medium. In the other hand, $3.75 \times 10^{6}$ calcein-PBMCs $/ \mathrm{ml}$ was prepared. Aliquots of $200 \mu \mathrm{l}$ calcein-PBMCs $\left(7.5 \times 10^{5}\right)$ were incubated in the presence of different concentrations of HP3 or HPNR $(0.2-2 \mathrm{pg} / \mathrm{ml})$ for $1 \mathrm{~h}$. These calcein-PBMCs pretreated with peptides were incubated in the top chamber of Transwells with HMVECs. To induce the migration of cells from the top chamber to the lower chamber of Transwells, $50 \mathrm{ng} / \mathrm{ml}$ of IL- 8 was added to the EBM medium contained in the lower chambers, and after $6 \mathrm{~h}$ of incubation at $37^{\circ} \mathrm{C}$ with $5 \% \mathrm{CO}_{2}$, the cells retrieved from the top and bottom chambers were counted in a cytometer. In the negative control assay, no IL-8 was added (NS, not stimulated). The experiment was repeated in five independent assays.

Treatment in imiquimod (IMQ)-induced mice with phages and peptides. All animal experiments were performed according to the appropriate guidelines for animal use approved by the Institutional Committee of Bioethics of the Escuela Nacional de Ciencias Biológicas-IPN, which follows the EU Directive 2010/63/EU on care for animals (ec.europa.eu/environment/chemicals/lab_animals/legislation_en.htm). A total of 50 female Balb/c mice (age, 8 weeks; weight, 22-25 g) were used in the present study. The animals were housed at $23^{\circ} \mathrm{C}$ with 12-h light/dark cycles, 40-60\% humidity and ad libitum access to food and water. The animals were supplied by the Animal Care Facilities of the Escuela Superior de Medicina-IPN.

The induction of psoriasis-like lesions in mice was performed according to van der Fits et al (22). Briefly, Balb/c mice were shaved on the dorsal region to allow free access of IMQ (Aldara ${ }^{\mathrm{TM}} 5 \%$ cream; Graceway Laboratory) to the skin. IMQ $(6.25 \mu \mathrm{g})$ was administered topically to the dorsal regions of mice daily for six days; after the third day of IMQ administration the psoriasis-like lesions were visible and after the sixth day the psoriasis-like lesions were clearly defined.

To arrest the development of psoriatic lesions, mice were treated intravenously (i.v.) with different concentrations of phages Ph3PBMCs or PhNR $\left(10^{5}, 10^{7}, 10^{9}\right.$ or $\left.10^{11} \mathrm{PFU}\right)$ on days 1-3, combined with topical treatment with IMQ; on days 4-6 mice were treated with imiquimod. For treatment with 

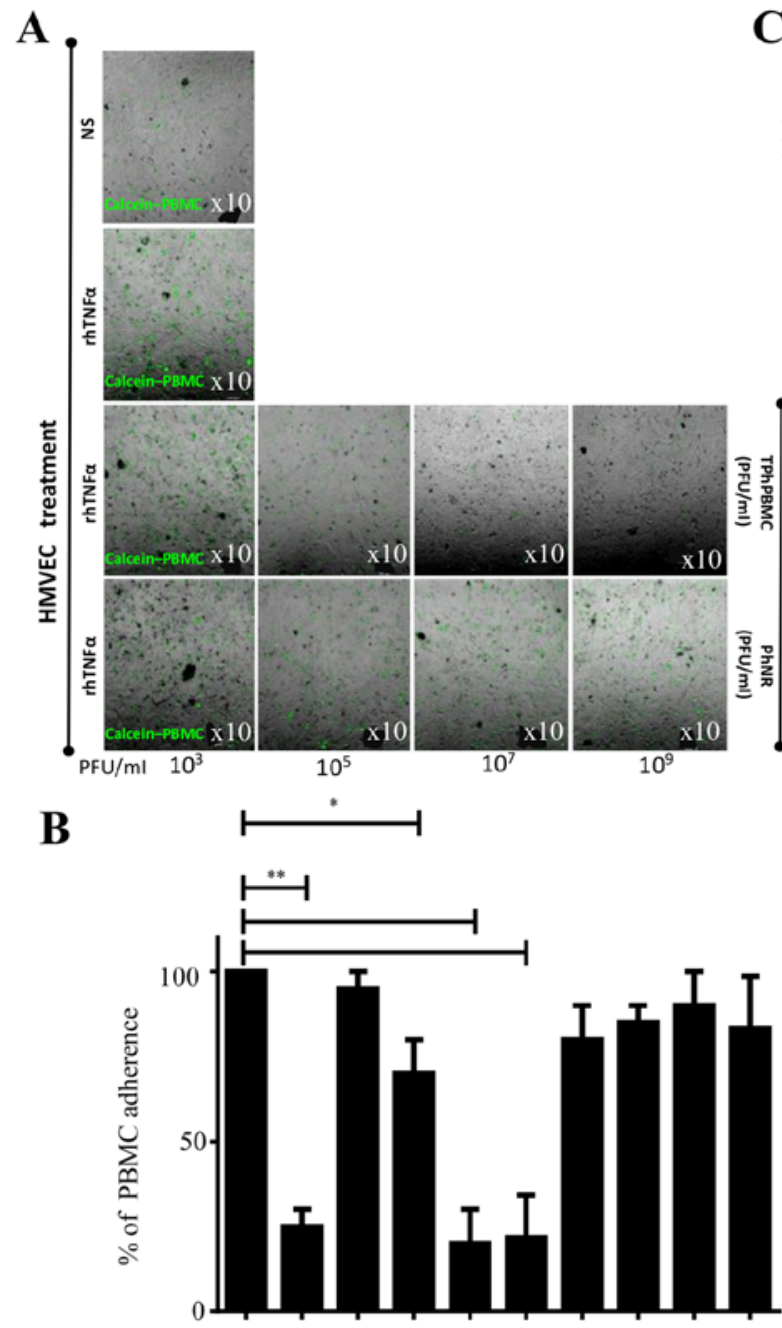

HMVEC + rhTNF $\alpha+$ $(50 \mathrm{ng} / \mathrm{ml})$

Calcein-PBMC

TPhPBMC (PFU/ml)

$$
\begin{gathered}
\mathrm{PhNR} \\
(\mathrm{PFU} / \mathrm{ml})
\end{gathered}
$$

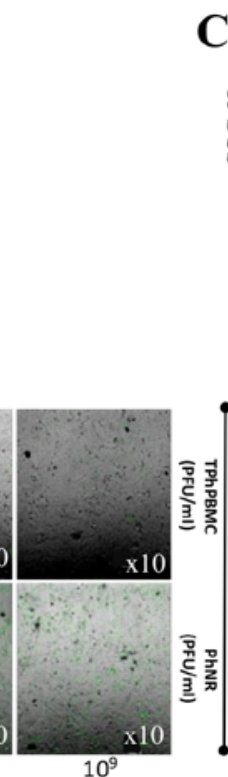

D
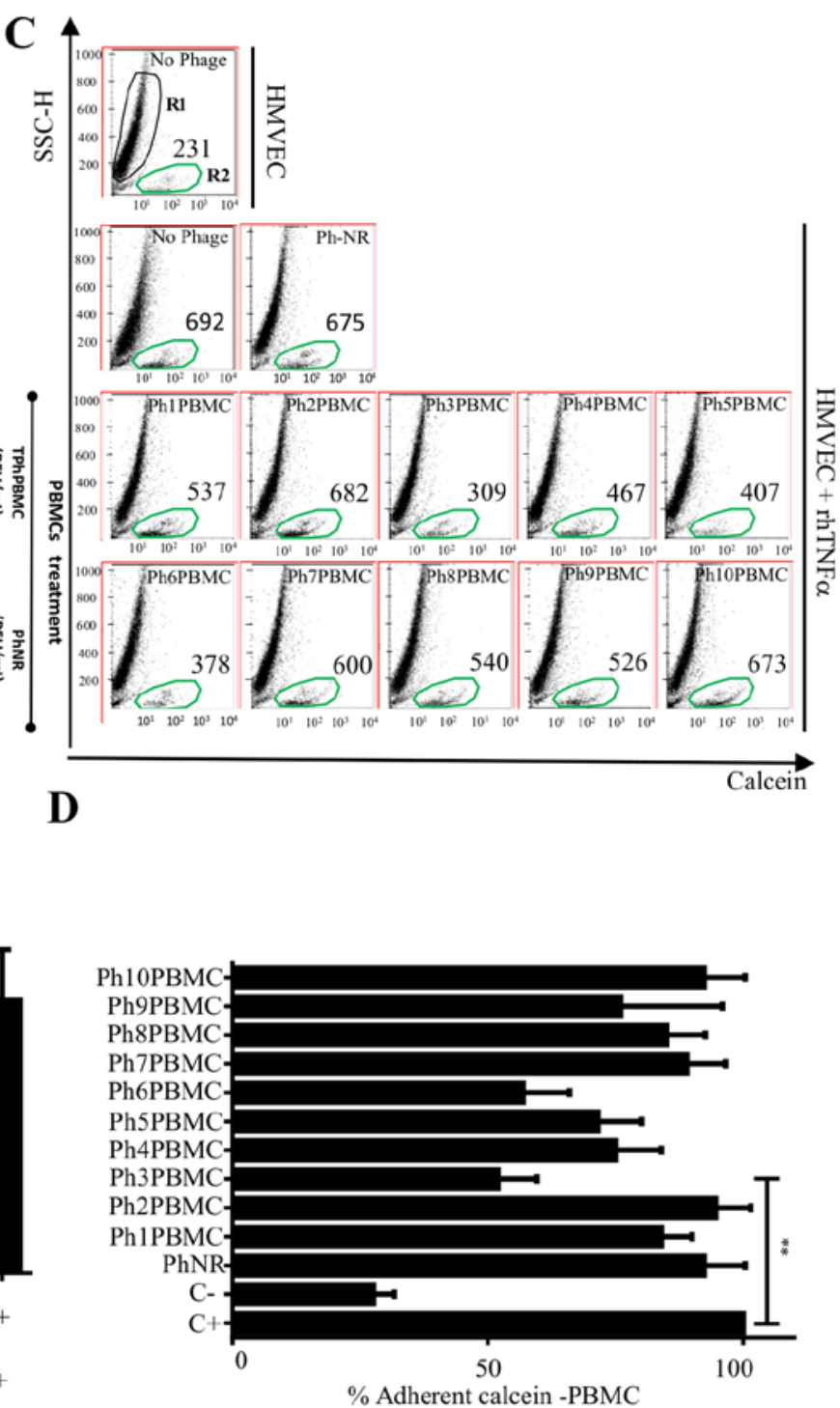

Figure 1. Adherence assay of PBMCs to HMVECs in the presence of TPhPBMCs. (A) HMVECs were stimulated or not with TNF $\alpha$ to induce adhesion molecules. Calcein-PBMCs pretreated with different concentrations of TPhPBMCs or PhNR phages $\left(10^{3}-10^{9} \mathrm{PFU}\right)$ were co-cultured with HMVECs and calcein-positive PBMCs adhered to HMVECs were observed under fluorescence microscope. (B) The same experiment as panel (A) but cells were enzymatically detached and calcein-positive PBMCs were counted with a cytometer. The graph shows the percentage of calcein-positive PBMCs. (C) Calcein-PBMCs pretreated with different clones of TPhPBMCs [Ph(1-10)PBMC] or PhNR phages were co-cultured with HMVECs, and calcein-positive cells that adhered to HMVECs were detached and counted by cytometry. R1, HMVECs; R2, calcein-positive PBMCs. The number of calcein-positive cells are indicated. (D) Graph indicates the percentage of calcein-positive PBMCs that adhered to HMVECs from four independent assays $\left(\mathrm{n}=4,{ }^{*} \mathrm{P}<0.05,{ }^{* *} \mathrm{P}<0.01\right.$, using one-way ANOVA and Dunnett's multiple comparison). PBMCs, peripheral blood mononuclear cells; HMVECs, human microvascular endothelial cells; TPhPBMCs, Total phages that interact with PBMCs TNF, tumor necrosis factor; PhNR, non-related phage; PFU, plaque forming units per milliliter; rh, recombinant human.

the synthetic peptide HP3 or HPNR (not related heptapeptide), mice were treated i.v. with different concentrations of peptides (0.01 $\mu \mathrm{g}$ or $10 \mu \mathrm{g}$ per mouse) dissolved in PBS on days $1-3$, combined with topical treatment with IMQ; on days 4-6 mice were treated with IMQ. On day 7, mice were sacrificed by intravenous injection of pentobarbital sodium $(150 \mathrm{mg} / \mathrm{kg})$ and animal death was confirmed by lack of reflexes, heartbeat and breathing.

Histochemistry. Skin biopsies $\left(1 \mathrm{~cm}^{2}\right)$ were removed from the back of the mice and maintained in a fixative formalin solution
(10\% in PBS) until use. The skin was placed into cassettes and dehydrated using an ethanol series $(70,80,90,96,100$ and $100 \%$ for $1 \mathrm{~h}$ each). Tissues were cleared twice in $100 \%$ xylene for $1 \mathrm{~h}$ and soaked in paraffin twice at $60^{\circ} \mathrm{C}$ for $1 \mathrm{~h}$. Subsequently, tissues were sectioned at $5 \mu \mathrm{m}$ using a Leica RM 2132 microtome (Leica Microsystems GmbH). Hematoxylin and eosin (H\&E) and Lillie's trichrome staining was done to the slides, with a staining time of $5 \mathrm{~min}$ at room temperature. Stained sections were observed in ten randomly selected fields of view using a transmitted light microscope (magnification, $x 40$ ). Histological examination and interpretation was performed blinded. 
Statistical analysis. Data are presented as the mean \pm SEM. Significant statistical difference among groups were determined using one-way ANOVA followed by Dunnett's post hoc test. Statistical analyses were performed using GraphPad Prism software (version 7.0d; GraphPad Software, Inc.). P $<0.05$ was considered to indicate a statistically significant difference.

\section{Results}

TPhPBMCs inhibit PBMC adhesion to HMVECs. HMVECs were treated with rhTNF $\alpha$ for $4 \mathrm{~h}$ to induce the expression of adhesion molecules (data not shown) and, in parallel, calcein-stained PBMCs were preincubated with TPhPBMCs or PhNR (see Materials and methods) for $2 \mathrm{~h}$ at different concentrations $\left(10^{3}-10^{9} \mathrm{PUF} / \mathrm{ml}\right)$. After several washes to remove the non-attached PBMCs, the calcein-stained PBMCs attached to the HMVEC monolayer were observed by fluorescent microscopy (Fig. 1A). When PBMCs were treated with TPhPBMCs the number of attached cells to HMVECs decreased in a concentration-dependent manner, even below basal condition (no rhTNFa stimulation; Fig. 1B). The inhibition of adhesion was specific for the treatment with TPhPBMCs, as it did not occur with PhNR.

Ph3PBMCs inhibit PBMC adhesion to HMVECs. For further elucidation, 10 clones of phages were randomly isolated from TPhPBMCs. Independent adhesion experiments were performed as previously described and to corroborate the results the proportion of calcein-positive PBMCs was also quantified by cytometry. The percentage of adherent calcein-positive PBMCs to HMVECs in the presence of each of the 10 isolated phage clones was determined. The maximum adherence $(110 \%)$ was considered as the number of calcein-positive PBMCs attached to rhTNF $\alpha$-stimulated HMVECs. Results showed that the clones Ph3PBMCs and Ph6PBMCs had the highest cell adhesion inhibition $(\mathrm{P} \leq 0.01)$ compared with C+ (Fig. 1C and D). Analysis of the heptapeptide sequence inserted in the phages identified that the clones Ph3PBMCs and Ph6PBMCs had the same heptapeptide sequence (data not shown).

Ph3PBMCs prevent the development of psoriasis-like lesions in a murine model. The effect of Ph3PBMCs treatment in the development of skin lesions was evaluated using the IMQ-induced psoriasis-like model (16). BALB/c mice were treated with IMQ for six days to induce psoriasis and during the first three days, they were also administered with different doses of Ph3PBMCs or PhNR $\left(10^{5}, 10^{7}, 10^{9}\right.$ or $10^{11} \mathrm{PFU} /$ mouse $)$ i.v. Fig. 2A shows squamous lesions in the back of mice and microscopic observations of skin biopsies (magnification, $\mathrm{x} 40$ ). It was observed that treatment with Ph3PBMCs prevented the development of psoriasis-like lesions in a dose-dependent mode in comparison with mice treated with PhNR. In mice treated with IMQ alone, the skin looked rigid and full of flakes and in histologic analysis the thickness of epidermis increased severely (hyperkeratosis). In mice treated with $10^{11} \mathrm{Ph} 3 \mathrm{PBMCs}$, the skin was soft with few small flakes and the thickness of epidermis was the same as untreated mice. Fig. 2B shows the epidermis thickness $(\mu \mathrm{m})$ data of treated mice and controls and it is clear that the administration of Ph3PBMCs decreased the thickness of the epidermis, while PhNR didn't have such effect.
A

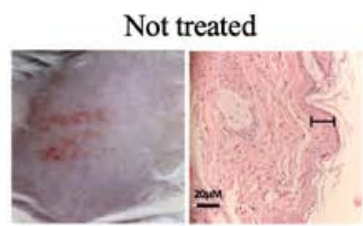

$\mathrm{IMQ}+\mathrm{Ph} 3 \mathrm{PBMC}$
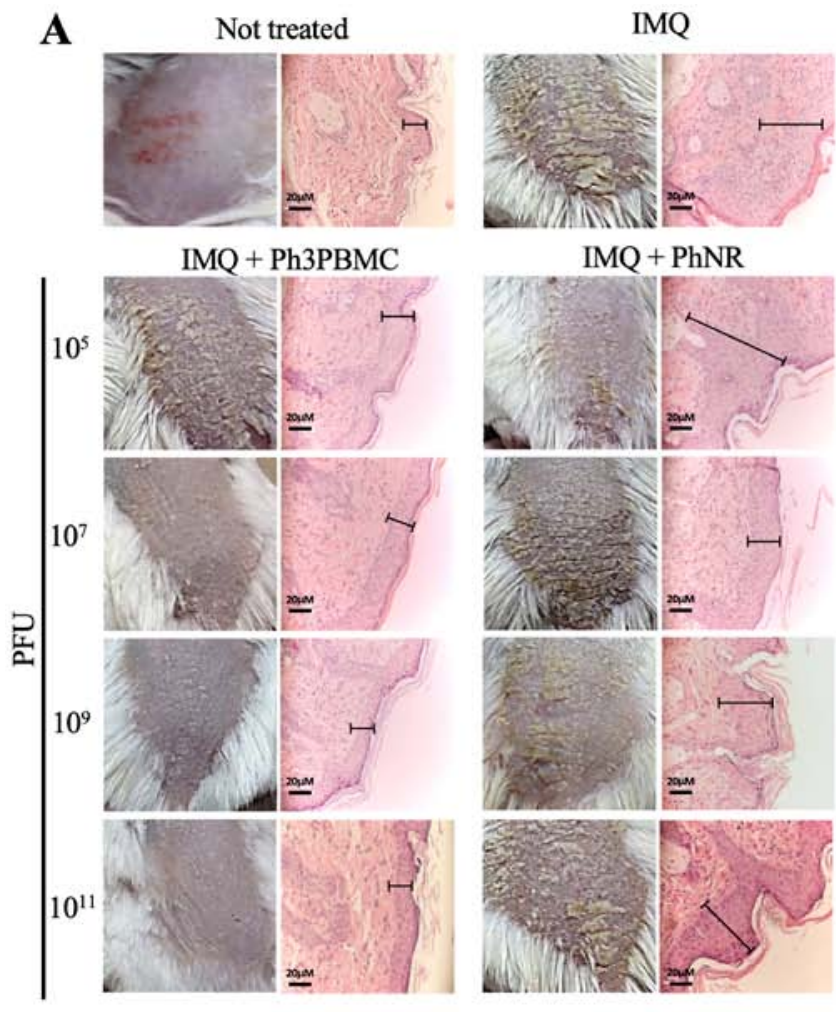

$\mathrm{IMQ}+\mathrm{PhNR}$

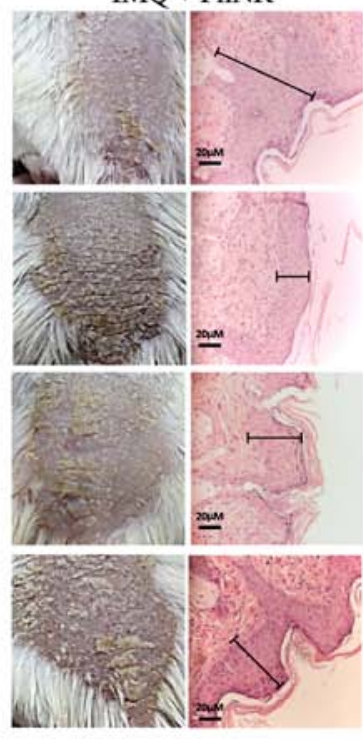

B

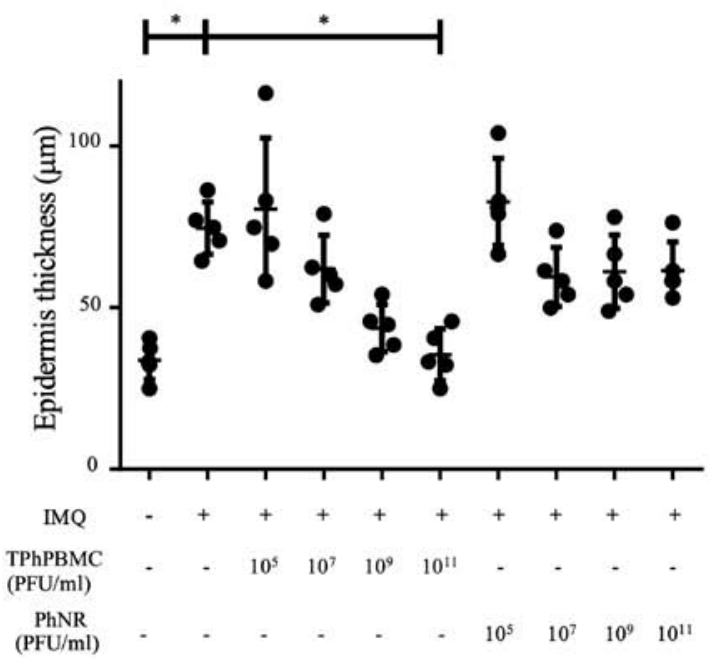

Figure 2. Treatment with Ph3PBMCs protects against psoriasis-like skin lesion development. IMQ-treated mice were also treated with different concentrations of phages $\left(10^{5}-10^{11} \mathrm{PFU}\right.$ of Ph3PBMCs or PhNR) i.v. on days 1, 2 and 3. Physiological solution with no phages was administered to those considered as positive control mice. (A) Skin lesions developed in the back of mice and microscopic observations of skin biopsies (x40). Thickness of epidermis is indicated with bars. (B) Graph indicates epidermis thickness $(\mu \mathrm{m})$ of phage-treated mice biopsies. $\mathrm{n}=5,{ }^{*} \mathrm{P}<0.05$ using one-way ANOVA, Dunnett's multiple comparison. Ph3PBMCs, phage 3 peripheral blood mononuclear cells; PhNR, non-related phage; $\mathrm{PFU}$, plaque forming units per milliliter; IMQ, imiquimod.

Peptide HP3 blocks adhesion of PBMCs to rhTNFa-induced HMVECs. It was also analyzed if the synthetic peptide (HP3) derived from the sequence of Ph3PBMCs could block the adherence of PBMCs to rhTNF $\alpha$-induced HMVECs. The adhesion assay was performed as previously described using $0.02,0.2$ or $2 \mathrm{pg} / \mathrm{ml}$ of peptide HP3 or $2 \mathrm{pg} / \mathrm{ml}$ of an unrelated heptapeptide (HPNR). Calcein-positive PBMCs 


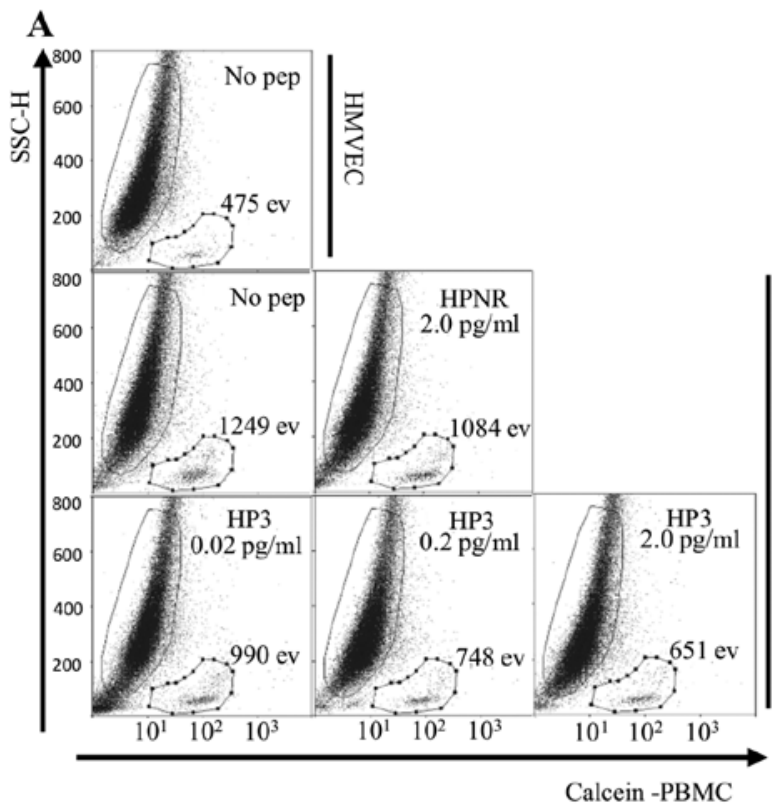

C
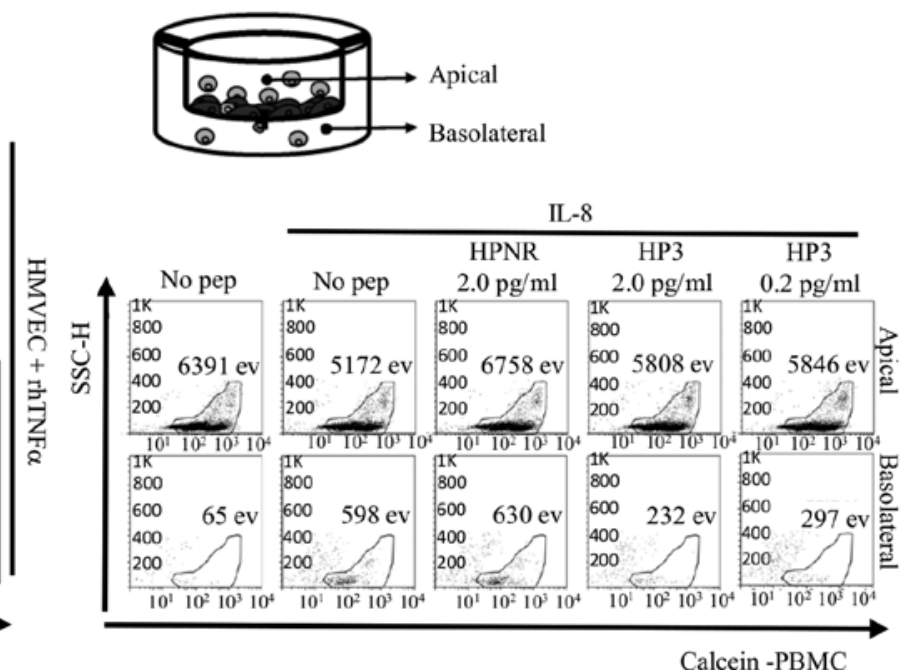

B

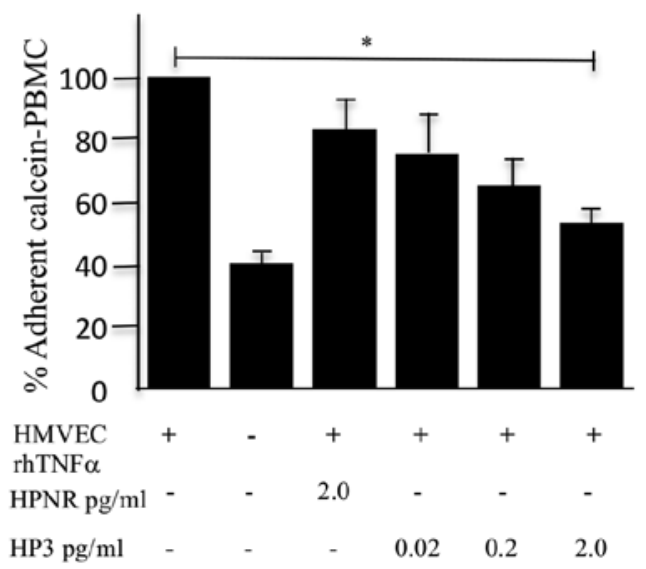

D

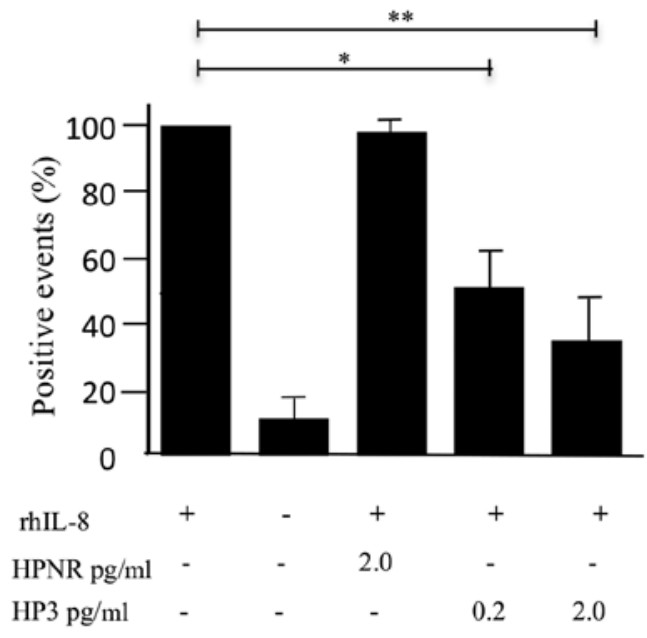

Figure 3. Adherence assay of PBMCs to HMVECs in the presence of peptide HP3 or HPNR. (A) Calcein-PBMCs pretreated with different concentrations of peptide HP3 or HPNR $(0.02,0.22 .0 \mathrm{pg} / \mathrm{ml})$ were co-cultured with HMVECs, and calcein-positive PBMCs adhered to HMVECs and enzymatically detached were detected by flow cytometry. The number of calcein-positive events is indicated. (B) Percentage of calcein-positive PBMCs adhered to HMVECs was determined. Graph represents the average of four independent assays. (C) Analysis of cell migration. Calcein-positive cells were pretreated with HP3 or HPNR, and co-cultured with HMVECs attached to the top side of Transwell plates. After $6 \mathrm{~h}$ of incubation the number of calcein-positive events were quantitated from the top and bottom sides of Transwell plates. (D) Percentage of cell migration is represented in the graph $\left(\mathrm{n}=4,{ }^{*} \mathrm{P}<0.05,{ }^{* *} \mathrm{P}<0.01\right.$, using one-way ANOVA and Dunnett's test). PBMCs, peripheral blood mononuclear cells; HMVECs, human microvascular endothelial cells; HPNR, non-related heptapeptide; TNF, tumor necrosis factor; rh, recombinant human.

were pretreated with the peptides and then co-cultured with rhTNF $\alpha$-induced HMVECs. After several gentle washes, the calcein-PBMC-positive cells were quantitated by flow cytometry (Fig. 3A) and the percentage of adherent PBMCs was calculated for each condition (Fig. 3B). The condition of HMVECs cultured with rhTNF $\alpha$ but without peptide treatment was deemed the maximum adhesion of PBMCs to HMVECs $(100 \%)$. According to the results shown in Fig. $3 \mathrm{~A}$ and B, the treatment with the peptide HP3 decreased the percentage of PBMCs attached to HMVECs as the concentration of HP3 was increased, demonstrating that the preincubation with $2.0 \mathrm{pg} / \mathrm{ml}$ of HP3 in PBMCs reduced their adherence to HMVECs to only $52.1 \%$ and, notably, the effect was not observed when HPNR was used.
HP3 inhibits the trans-endothelial migration of monocytes. To evaluate if HP3 could inhibit the trans-endothelial migration of PBMCs, an in vitro assay was performed using Transwell plates. HMVECs and calcein-positive PBMCs were co-cultured in the top compartment of Transwell plates and then the effect of HP3 in the migration of calcein-positive PBMCs to the bottom compartment in the presence of the chemoattractant IL-8 was evaluated. As shown in Fig. 3C, the bottom side of Transwell contained $13.5 \%$ of cells in basal culture conditions and it increased to $26.1 \%$ in the presence of IL-8. However, when calcein-PBMCs cells were pretreated with HP3 the migration decreased considerably to $11.6 \%$ with $0.2 \mathrm{pg} / \mathrm{ml}$ of HP3 and to $11.2 \%$ with $2.0 \mathrm{pg} / \mathrm{ml}$ of HP3, in contrast to the treatment with HPNR that remained close to the control condition (28.4\%). 
Fig. 3D, represents the mean of cell migration assay percentages of calcein-positive PBMCs from 4 independent experiments.

HP3 prevents the development of psoriasis-like lesions in a murine model. Peptide HP3 (0.01 or $10 \mu \mathrm{g})$ or HPNR $(10 \mu \mathrm{g})$ was administered i.v. in the tail of mice in the first three days of psoriasis induction protocol, as previously described. According to the results shown in Fig. 4, the treatment with HP3 decreased the severity of psoriasis-like lesions even at $0.01 \mu \mathrm{g} / \mathrm{mouse}$ doses, but more clearly at a dose of $10 \mu \mathrm{g} / \mathrm{mouse}$. In addition to the formation of squamous lesions, angiogenesis is also increased in psoriatic lesions and when the inner side of the skin was analyzed, a higher number and thickness of blood vessels was observed in the IMQ-treated skins and an apparent decrease of angiogenesis in HP3-treated skins (Fig. 4A). To confirm these observations, sections of skin biopsies were stained with Lillie's trichrome and a lower number of blood vessels were found in peptide HP3-treated mice (arrowheads Fig. 4A) compared with peptide HPNR treatment. The thickness of the skin was measured in slides stained with hematoxylin and eosin (H\&E) (Fig. 4B) and it was observed that both concentrations of peptide HP3 decreased the thickness of the treated skin. Van der Fits et al (22) reported that mice treated with IMQ for psoriasis induction also develop splenomegaly, therefore it was decided to analyze the spleen index in mice treated with the peptide. The treatment with peptide HP3 also reduced the spleen index, reflecting a systemic effect in the general health of IMQ-induced mice treated with HP3 as demonstrated in Fig. 4C.

The results of the present study demonstrated that peptide HP3 reduced the adhesion of PBMCs to endothelial cells, affecting their migration through endothelial cells and frustrating their participation in the inflammatory processes. In the murine model of psoriasis, the treatment with HP3 in IMQ-induced mice reduced the development of skin lesions diminishing the thickness of the skin, the formation of squamous skin and angiogenesis, and as a systemic effect prevents the development of splenomegaly. This suggests a potential use of HP3 to treat psoriasis in humans.

\section{Discussion}

There are different treatments for psoriatic patients used according to their afflictions. The treatments can be phototherapy, systemics or biologicals. The drugs used to treat psoriasis block the action of specific $\mathrm{T}$ cell population, or block the activity of proteins such as TNFa (golimumab, infliximab, adalimumab, etanercept and certolizumab pegol), IL-17A (secukinumab and ixekizumab), IL-17 receptor (brodalumab) or IL-12/IL-23 (ustekinumab and tildrakizumab). These targeted cells and proteins all play significant roles in developing psoriasis and psoriatic arthritis (23).

The use of monoclonal antibodies as therapeutics has provided an efficient way to inhibit proteins (ligands or receptors) for the treatment of diverse diseases, but in a long-term treatment its efficiency decreases as a result of resistance, such as the generation of antibodies against the monoclonal antibodies, or the formation of immunocomplexes. Other common side effects for these treatments are respiratory infections and flu-like symptoms, but also include severe side effects such as
A Imiquimod

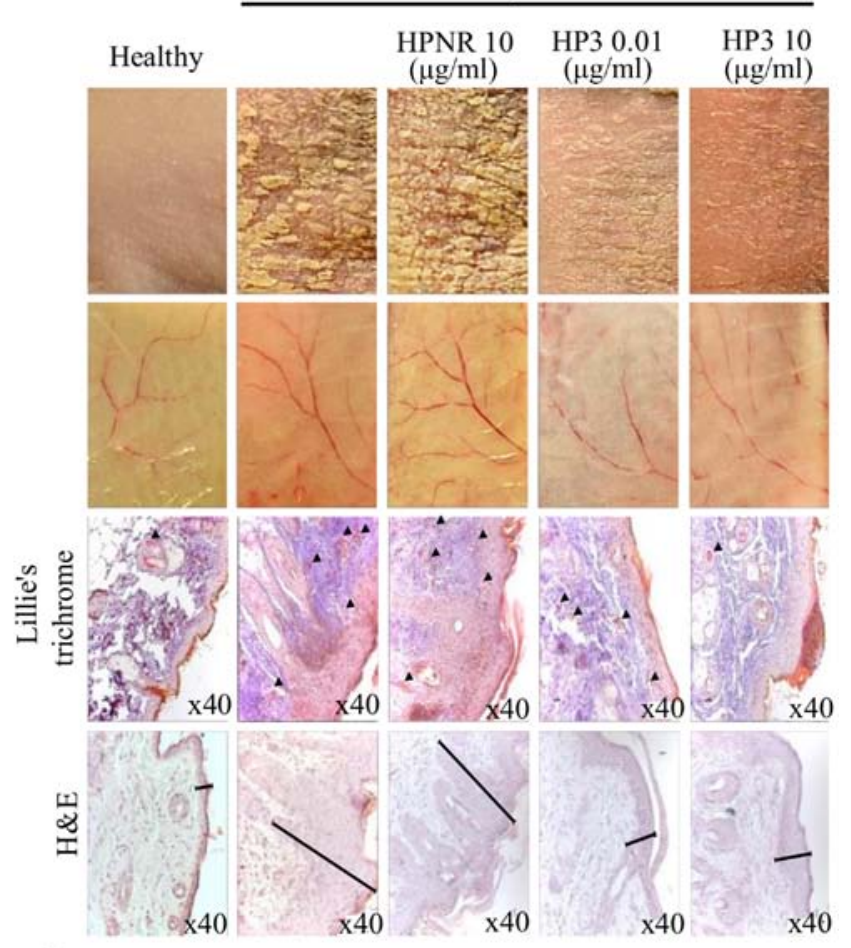

B

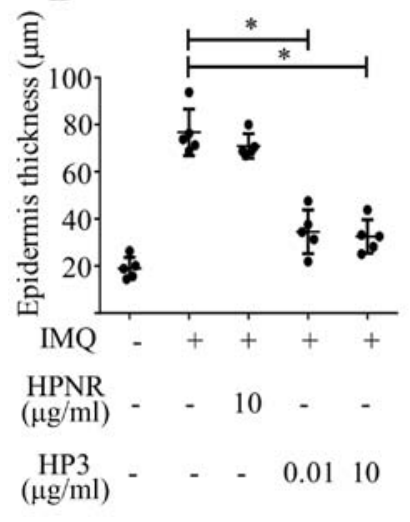

C

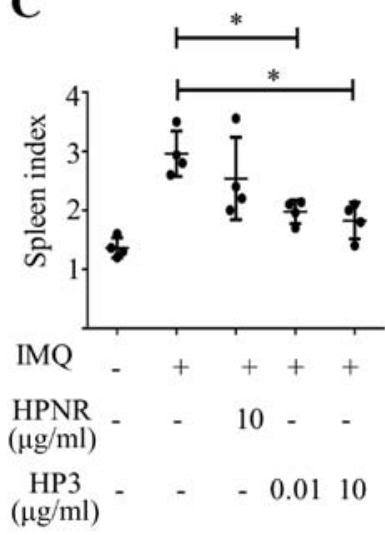

Figure 4. Treatment with peptide HP3 protects against psoriasis-like skin lesions development. Mice were treated i.v. with different concentrations of peptides HP3 or HPNR ( 0.01 and $10 \mu \mathrm{g}$ per mice) on days 1-3, as well as imiquimod. On days 4-6 mice were treated only with imiquimod. Some mice were also treated only with vehicle (negative control) or only with imiquimod (positive control). (A) Skin lesions from the back of mice are shown, and slides of skin biopsies were stained with Lille's trichrome solution. Arrowheads show blood vessels. The thickness of the skins is indicated in slides stained with $\mathrm{H} \& \mathrm{E}$. (B) Epidermal skin thickness of peptide-treated mice biopsies $\left(\mathrm{n}=5,{ }^{*} \mathrm{P}<0.05\right.$, using one-way ANOVA, Dunnett's multiple comparison). (C) Spleen index related to splenomegaly ( $\mathrm{n}=5$, " $\mathrm{P}<0.05$, using one-way ANOVA and Dunnett's multiple comparison). HPNR, non-related heptapeptide; H\&E, hematoxylin and eosin; IMQ, imiquimod.

blood and nervous system disorders, inflammation of nerves of the eye and even certain types of cancer (24). Thus then, the generation of different approaches to create new treatments remains crucial. The number of peptides entering clinical development is increasing. In 2018, Lau and Dunn reported information about the existence of 484 therapeutic peptides; from these, 155 peptides were actively in clinical development, $10 \%$ in phase I, $16 \%$ in phase II, $5 \%$ in phase III and $5.1 \%$ in preregistration (25). 
The peptide HP3 was obtained from the sequence of a phage-peptide clone with interaction with human PBMCs. The in vitro assays were performed with human cells, but the in vivo assays were performed using a murine model of psoriasis. According to the results of the present study, the peptide blocks the adherence and migration of PBMCs in both species, suggesting that the specific ligand/receptor that is blocked is shared between both species. Sequence analysis of the peptide showed that it has $73 \%$ of homology with human CCR2 (data not shown) but also affinity to a receptor of $\mathrm{T}$ cells. Further studies are necessary to define the specific molecule that is recognized by the peptide.

The results of the present study demonstrated that peptide HP3 can reduce the adhesion of human PBMCs to endothelial cells, affecting the migration of cells and, as consequence, interfering in their availability to participate in the development of inflammation, as observed in the psoriasis-like murine model, where the treatment with the peptide protects against the generation of lesions in the skin. The same effect could occur in human psoriasis. In such a case, this peptide could be used for the treatment of human psoriasis.

\section{Acknowledgements}

The authors would like to thank Dr Eugenia Aguilar Nájera from the Animal Care Facilities of the Escuela Superior de Medicina-IPN for supplying the mice used in this work.

\section{Funding}

The present study was supported by IPN-Multidisciplinary Projects SIP-1773 and SIP-20149. LAZC and GGG received postgraduate scholarships from CONACyT and BEIFI-IPN. SRM, JCCD, MECD, TAM and SMPT are COFAA-IPN, EDI-IPN and SNI-CONACyT Fellows. FGC is Cátedra-CONACyT and SNI-CONACyT Research Fellow.

\section{Availability of data and materials}

The datasets analyzed during the present study are available from the corresponding author on reasonable request.

\section{Authors' contributions}

MECD, JCCD and SRM designed the study. JSMF performed the biopanning assay. PEBL performed the adherence assay. LAZC, ATC and GGG performed the psoriasis experiments. IDT analyzed the in silico results. SMPT, FGC and MECD analyzed the data and wrote the manuscript. EAVS performed the histochemistry assays. All authors read and approved the final manuscript.

\section{Ethics approval and consent to participate}

All experimental procedures, including the purification of human mononuclear cells, treatment with psoriasis inductors, administration of phages or peptides and death of animals, were approved and performed according to the standards of the Ethics Committee of the Instituto Politécnico Nacional/Escuela Nacional de Ciencias Biológicas. The registration and approval of the protocol of mice usage is under the file number
ENCB/CEI/036/2018, CONBIOETICA09CEI03720130520 and the approval of the protocol of human samples usages is under the file number CEI-ENCB-SH-002-2018.

\section{Patient consent for publication}

Not applicable.

\section{Competing interests}

The authors declare that they have no competing interests.

\section{References}

1. Hickey MJ, Reinhardt PH, Ostrovsky L, Jones WM, Jutila MA, Payne D, Elliott J and Kubes P: Tumor necrosis factor-alpha induces leukocyte recruitment by different mechanisms in vivo and in vitro. J Immunol 158: 3391-3400, 1997.

2. Li Q, Chandran V, Tsoi L, O'Rielly D, Nair RP, Gladman D, Elder JT and Rahman P: Quantifying differences in heritability among psoriatic arthritis (PsA), cutaneous psoriasis (PsC) and psoriasis vulgaris (PsV). Sci Rep 10: 4925, 2020.

3. Beurskens T, Chang A, van Erp PE and van de Kerkhof PC: Epidermal proliferation and accumulation of polymorphonuclear leukocytes in the psoriatic lesion. Dermatologica 178: 67-72, 1989.

4. Schlaak JF, Buslau M, Jochum W, Hermann E, Girndt M, Gallati H, Meyer zum Büschenfelde KH and Fleischer B: T cells involved in psoriasis vulgaris belong to the Th1 subset. J Invest Dermatol 102: 145-149, 1994.

5. Nestle FO, Di Meglio P, Qin JZ and Nickoloff BJ: Skin immune sentinels in health and disease. Nat Rev Immunol 9: 679-691, 2009.

6. Singh K, Gatzka M, Peters T, Borkner L, Hainzl A, Wang H, Sindrilaru A and Scharffetter-Kochanek K: Reduced CD18 levels drive regulatory T cell conversion into Th17 cells in the CD18hypo PL/J mouse model of psoriasis. J Immunol 190: 2544-2553, 2013.

7. He Q, Chen HX, Li W, Wu Y, Chen SJ, Yue Q, Xiao M and Li JW: IL-36 cytokine expression and its relationship with p38 MAPK and NF- $\mathrm{B}$ pathways in psoriasis vulgaris skin lesions. J Huazhong Univ Sci Technolog Med Sci 33: 594-599, 2013.

8. Nedoszytko B, Sokołowska-Wojdyło M, RuckemannDziurdzińska K, Roszkiewicz J and Nowicki RJ: Chemokines and cytokines network in the pathogenesis of the inflammatory skin diseases: Atopic dermatitis, psoriasis and skin mastocytosis. Postepy Dermatol Alergol 31: 84-91, 2014.

9. Alexander H and Nestle FO: Pathogenesis and immunotherapy in cutaneous psoriasis. what can rheumatologists learn? Curr Opin Rheumatol 29: 71-78, 2017.

10. Guenther L, Van De Kerkhof PC, Snellman E, Kragballe K, Chu AC, Tegner E, Garcia-Diez A and Springborg J: Efficacy and safety of a new combination of calcipotriol and betamethasone dipropionate (once or twice daily) compared to calcipotriol (twice daily) in the treatment of psoriasis vulgaris: A randomized, double-blind, vehicle-controlled clinical trial. Br J Dermatol 147: 316-323, 2002.

11. Shah RA, Nwannunu CE, Limmer AL, Patel RR, Mui UN and Tyring SK: Brief update on dermatologic uses of methotrexate. Skin Therapy Lett 24: 5-8, 2019.

12. Krueger $\mathrm{G}$ and Callis K: Potential of tumor necrosis factor inhibitors in psoriasis and psoriatic arthritis. Arch Dermatol 140: 218-225, 2004.

13. Ryan C, Leonardi CL, Krueger JG, Kimball AB, Strober BE, Gordon KB, Langley RG, de Lemos JA, Daoud Y, Blankenship D, et al: Association between biologic therapies for chronic plaque psoriasis and cardiovascular events: A meta-analysis of randomized controlled trials. JAMA 306: 864-871, 2011.

14. Tzellos T, Kyrgidis A, Trigoni A and Zouboulis CC: Point: Major adverse cardiovascular events and anti-IL 12/23 agents. J Am Acad Dermatol 70: 380-381, 2014.

15. Thaçi D, Blauvelt A, Reich K, Tsai TF, Vanaclocha F, Kingo K, Ziv M,Pinter A, Hugot S, You R and Milutinovic M: Secukinumab is superior to ustekinumab in clearing skin of subjects with moderate to severe plaque psoriasis: CLEAR, a randomized controlled trial. J Am Acad Dermatol 73: 400-409, 2015.

16. Gordon KB, Blauvelt A, Papp KA, Langley RG, Luger T, Ohtsuki M, Reich K, Amato D, Ball SG, Braun DK, et al: Phase 3 trials of ixekizumab in moderate-to-severe plaque psoriasis. N Engl J Med 375: 345-356, 2016. 
17. Su Z, Paulsboe S, Wetter J, Salte K, Kannan A, Mathew S, Horowitz A, Gerstein C, Namovic M, Todorović V, et al: IL-36 receptor antagonistic antibodies inhibit inflammatory responses in preclinical models of psoriasiform dermatitis. Exp Dermatol 28: 113-120, 2019.

18. Rossi B and Constantin G: Anti-selectin therapy for the treatment of inflammatory diseases. Inflamm Allergy Drug Targets 7: 85-93, 2008.

19. Rychly $\mathrm{J}$ and Nebe B: Therapeutic strategies in autoimmune diseases by interfering with leukocyte endothelium interaction. Curr Pharm Des 12: 3799-3806, 2006.

20. Radi ZA, Kehrli ME Jr and Ackermann MR: Cell adhesion molecules, leukocyte trafficking, and strategies to reduce leukocyte infiltration. J Vet Intern Med 15: 516-529, 2001.

21. Koo JY, Bagel J, Sweetser MT and Ticho BS: Alefacept in combination with ultraviolet B phototherapy for the treatment of chronic plaque psoriasis: Results from an open-label, multicenter study. J Drugs Dermatol 5: 623-628, 2006.

22. van der Fits L, Mourits S, Voerman JS, Kant M, Boon L, Laman JD, Cornelissen F, Mus AM, Florencia E, Prens EP and Lubberts E: Imiquimod-induced psoriasis-like skin inflammation in mice is mediated via the IL-23/IL-17 axis. J Immunol 182: 5836-5845, 2009.
23. Strober BE, Bissonnette R, Fiorentino D, Kimball AB, Naldi L, Shear NH, Goyal K, Fakharzadeh S, Calabro S, Langholff $\mathrm{W}$, et al: Comparative effectiveness of biologic agents for the treatment of psoriasis in a real-world setting: Results from a large, prospective, observational study [Psoriasis Longitudinal Assessment and Registry (PSOLAR)]. J Am Acad Dermatol 74: 851-861.e4, 2016.

24. Branisteanu DE, Voicu CM, Cretu A, Dimitriu A, Luca MC and Salavastru CM: Adverse reactions of biological therapy for psoriasis. Rev Med Chir Soc Med Nat Iasi 119: 38-44, 2015.

25. Lau JL and Dunn MK: Therapeutic peptides: Historical perspectives, current development trends, and future directions. Bioorg Med Chem 26: 2700-2707, 2018.

(i) $($ ) This work is licensed under a Creative Commons Attribution-NonCommercial-NoDerivatives 4.0 International (CC BY-NC-ND 4.0) License. 